\title{
The Collaborative Construction of Intersubjectivity Mediated by Technology: A Social-Biological Model of Online Communication
}

\author{
Leon James* \\ Department of Psychology, Professor of Psychology, University of Hawaii, Honolulu, USA
}

Received: December 11, 2013; Accepted: April 26, 2014; Published: April 28, 2014

*Corresponding author: Leon James, Department of Psychology, Professor of Psychology, University of Hawaii, 2430 Campus Road, Honolulu, HI 96822, USA, Tel: 808-295-2702; Fax: 808-261-2382; Email: leon@hawaii.edu

\begin{abstract}
A theory is presented for understanding the construction and development of group intersubjectivity, defined as the joint infosphere produced through collaborative activity. A model is presented that represents online social networking as an integrated social-biological technology. The schema depicts the flow of interactions both within an individual participant and between participants who are engaged in the collaborative activity online. The model shows how the three human biological sub-systems form a symbiosis with technology through the body's sensorimotor interface, and how this interacts with the cognitive and affective biological sub-systems that create the interaction flow. All technology is interpreted in terms of satisficing affordances and optimizing affordances in relation to the three biological sub-systems. This model would allow a charting method for the study of progressive interactionism that characterizes successful goal-motivated group cooperation and online community building.
\end{abstract}

"The individual experiences himself as such, not directly, but only indirectly, from the particular standpoints of other individual members of the same social group, or from the generalized standpoint of the social group as a whole to which he belongs." (p. 138) "We are what we are through our relationship to others" [1].

\section{The Construction of Collaborative Intersubjectivity}

Habermas [2] describes society as a sphere of intersubjectivity created through the actions and interactions of people who see themselves as the conscious creators of values and meanings. Habermas argues that intersubjectivity is the collaborative outcome of many individual "subjectivities" and has its own autonomous existence.

Intersubjectivity is seen as a continually changing and evolving sphere of human consciousness. Language, speech and verbal interactions constitute a technological medium for "coordinating symbolically mediated action" involving the "goaldirected actions of participants" (Habermas, v.1 p.23, 101). A distinction is drawn between (i) language as content and (ii) speech as social action. Habermas gives credit to Mead [1] who developed the approach of progressive "symbolic interactionism" as the basis of the formation of self and society. Mead described the mechanism of intersubjectivity as the interaction between participants "who adjust to one another and reciprocally take positions on one another's utterances."

In this view, learning anything is not the individual acquisition of knowledge but the joining of the group as a member. To participate as a member is to act like others with respect to perceptions, meanings, values, and intentions. The activity of participating or interacting is the learning.

Habermas [2] defined communication as social interaction in which "the actors seek to reach an understanding about the action situation and their plans of action in order to coordinate their actions by way of agreement" (p.86). Practical knowledge is not something people acquire by learning but rather emerges in the "communicative action" that is driven by the activity and its social context. The contrast to communicative action is "instrumental mastery" which tends to be constructivist [not constructionist] or "hermeneutic" (p.11). Individual consciousness attained in this way is "merely subjective", "egocentric" and closed (does not evolve), while intersubjectivity is objective, communal, and open (expands and grows).

According to Habermas participatory interactionism is essential for the growth of objective consciousness and "critical" rationality. In an "ideal communicative community" participatory interaction produces "the emergence of a higherlevel form of life" [2]. There are two forms of rationality or intelligences: instrumental and communicative. Instrumental intelligence is taxonomic while communicative intelligence is generative and predictive. Communication networks and classification schemes may be called horizontal ecologies while meanings produced in generative discourse may be called vertical ecologies. Collaborative interactions are communicative, generated by discourse exchanges, and hence are developmental and incremental.

The global infosphere Floridi [3] is seen as an expanding space of intersubjectivity arranged in consciousness zones or activities. The World Wide Web has a horizontal and a vertical 
component. The words "network" and "Internet" refer to the physical technology that provides global connectivity through computers geographically distributed and identified uniquely. This vast and rapidly expanding horizontal communication ecology is the physical embodiment of a vertical ecology that is populated by mental consciousness of human meanings and values.

The theory of ecological constructionism through socialbiological technology, as described further below, gives an objective account of how the vertical ecology of mental consciousness is constructed by participants through the activity of interacting with each other on a continuous basis in real life settings through the medium of computer systems and other artifacts. The word intersubjectivity refers to the shared mental consciousness that is produced between participants who use technology to engage each other in progressive interactions in a real life situation. During interaction, each participant processes individual thoughts and feelings that relate to each other through shared group meanings and values. A theory is presented below that describes the mechanism that produces intersubjectivity.

A method is needed for charting the interaction of users when they are engaged in teamwork or other cooperative online activities and coordinated events. The concept of progressive interactionism refers to the idea that interaction itself is responsible for the emergence of successful goal-motivated group cooperation and online community building. It is logical to expect that the potential for achieving a goal is greater when a group of individuals combine to cooperate together, as opposed to single individuals working independently and alone [4]. Besides the fact of sheer numbers in the group, there is the interaction itself that promotes and encourages the emergence of a solution. Individuals react to one another as they interact and as they process each other's communicative acts. Their reaction in turn affects the others in a cumulative direction that is progressive and goal-oriented, leading to the emergence of solutions.

The charting method should make it visibly clear how the interactions in an information network take place through the integration of technology and users engaged in progressive interactions. It is clear that the interactions between users is delimited or influenced by the properties of the technology in terms of how the interface allows users to encode their cognitive and affective reactions so that these may become known to the others. Gibson \& Pick [5-11] have discussed these humanmachine integrations as involving two types, namely satisficing and optimizing affordances.

These terms accurately depict the cognitive, evaluative, and motivational involvements of users with technological interfaces. Users perform standard satisficing procedures when they react to a display or message and fill in its cognitive context with meaning that relates to the interaction. Users then evaluate the meaning of that display or message, seeing it as relevant and valuable, or not. The satisficing of a member's communicative act or intervention is biologically followed by a conative intentionality or goal-directed motivation that involves optimizing procedures of intending, planning, and executing a communicative act that is transmitted to the others through the affordances provided by the particular interface (e.g., clicking, typing, or displaying an image).

Online socializing and collaborative tasks consist of a progressive series of satisficing and optimizing interactions mediated by technological affordances. The model makes it clear that these interactions involve the three human biological operations integrated with the affordances that are made available by the interface.

\section{Vertical and Horizontal Information Networks}

The infosphere is a vertical ecology that is expanding through the construction of collaborative intersubjectivity that is embodied in the interactions of the participants. The expanding horizontal technology of interfaces supports the progressive growth of this intersubjective infosphere. All human interactions are collaborative because they require mutual coordination by the interactants in the activity of satisficing and optimizing each other's communicative acts or interventions. Like all activity, an interaction is always situated in place and time and involves three components:

(a) Participants who perform individualbiological operations (i.e., sensorimotor, cognitive, affective)

(b) Shared social practicesthat regulate each participant's biological operations

(c) Environmental affordances that mediate the human interactions (e.g., computer interfaces and online networks).

These three components acting together in synergy constitute a social-biological technology [11]. It is the three-way framework that creates the vertical ecology of the infosphere. Online communities and groups in this infosphere are defined and delimited by the progressive interactions of participants who form groups on the basis of expressed interest or involvement in particular topics and goals. The simplest kind of group formation consists of a mere Like or other endorsement (Friends, Follower) by which one person joins others in a sub-group with the same involvement and compatible meaning.

The theory makes visible how intersubjectivity is built up by the coordinated interactional flow of biological operations by participants who react to one another. For instance, when a person sends a message using optimizing affordances (e.g., email or messaging), it becomes the initiating step of a series of subsequent interactive steps to be taken by both individuals in turn, such as:

(i) reading the received message (i.e., sensorimotor operation with satisficing affordances)

(ii) planning to answer with a message (i.e., cognitive operation with optimizing affordance)

(iii) forwarding the message to someone else (i.e., sensorimotor operation with optimizing affordances)

(iv) expecting a certain kind of response that will require 
another answer (i.e., cognitive operation with both satisficing and optimizing affordances)

(v) and so on.

This progressive interactionism is regulated by social practices that each individual assimilates and adapts to by being a participant. The model presents a dynamic flow showing the three sequential biological operations that each participant performs in order to achieve

(i) joint attention to the available technological affordances involving the sensorimotor system (e.g., text messages, notifications, attachments, links, alarms, requests, etc.)

(ii) shared meanings and plans involving the cognitive system

(iii) collaborative intentions involving the affective system (e.g., goals, agreements, mutual support, inclusion, urgency, etc.)

This progressive cycle of interactivity involving coordinated mental operations of the participants is the activity in which intersubjectivity is embodied and exists. It is the "being of the infosphere" [3].

\section{Ecological Constructionism Model}

Figures 1 and 2 show how communicative rationality is jointly constructed by participants through repeated cycles of satisficing and optimizing each other's acts through the threefold biological system that is managed by each individual.

To specify theoretically what people do when they interact with technology requires a minimal conceptual framework that includes the following three components:

(1) Social settings that provide the cultural content of information and its relevance to group sanctioned norms and values as practiced by participants with each other.

(2) Biological systems that interact with technological artifacts through the sensorimotor system (eyes, hands, voice, ears), and can process information by the cognitive system (appraising and planning) which is under the control of the affective system (evaluating, intending).

(3) Technological systems that display information and take commands from participants through an interface that is engineered for symbiotic interactions with human biological capabilities. Some artifacts like screen displaysprovide for noticing information (satisficing affordance), while other artifacts like mouse, keyboard or hyperlink, provide for optimizing information by allowing participants to modify the display environment.

Social-biological information technology is a symbiotic integration of three distinct systems: social, biological, and technological. The framework shown in Figure 1 exhibits the

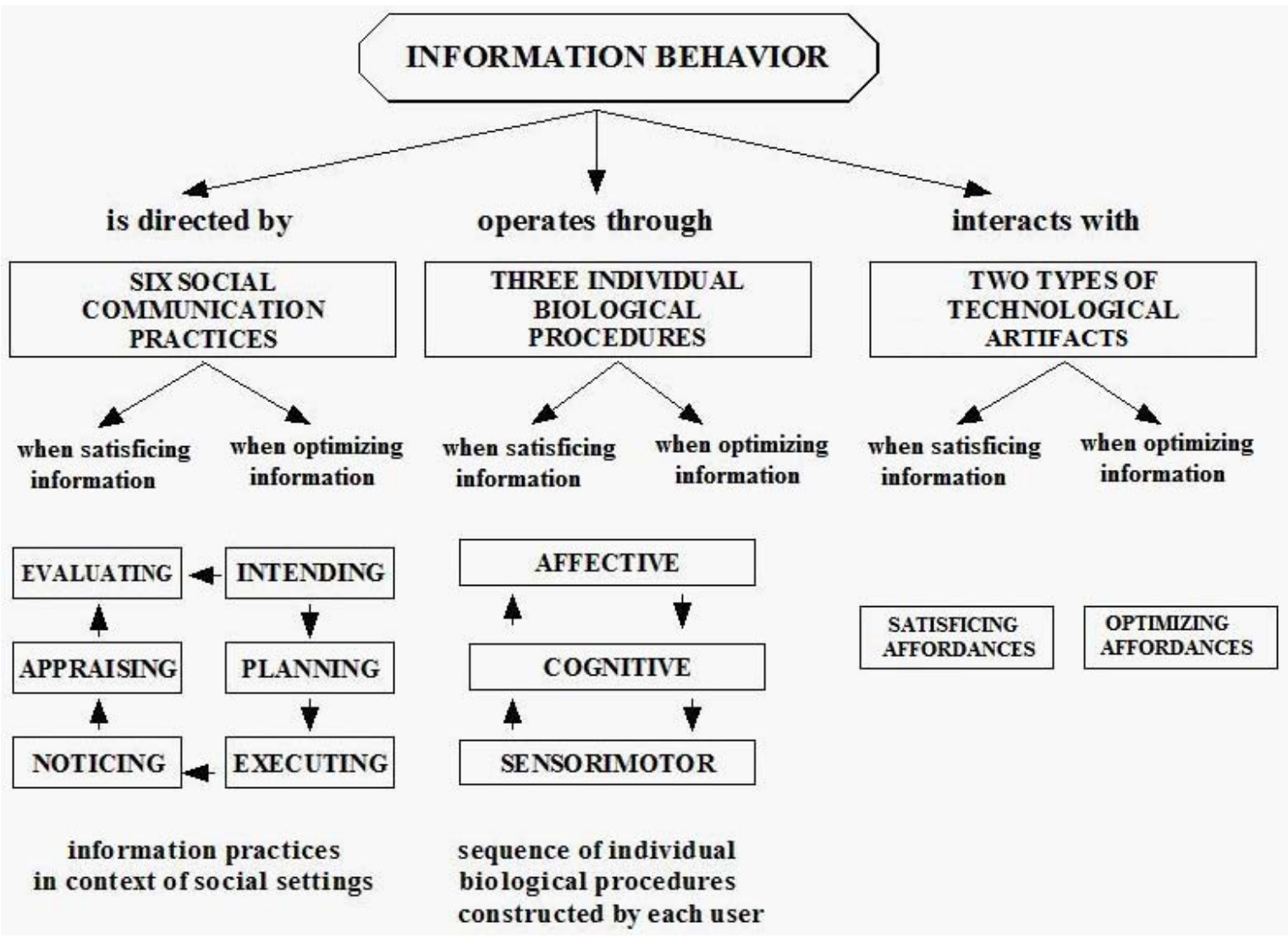

Figure 1: Social-Biological Information Technology. 
distinct role of each of these three intersecting components that form the context of collaborative interaction mediated by technology:

(1) social communication practices in a community or population

(2) biological operations that people perform during interactions

(3) technological artifacts or affordancesdesigned to display information and receive commands.

Of the three components of the symbiotic framework, the biological system is fixed while the social and technological systems must be made to adapt to the biological capabilities of humans. The ecological framework is therefore keyed to the three biological sub-systems traditionally known in psychology and medicine as the affective sub-system, the cognitive subsystem, and the sensorimotor sub-system [13].

The sensorimotor sub-system functions as the neurobiological interface connecting human and machine as it senses, filters, and notices machine generated information displays or signals, and at the same time handles or operates the machine's input devices. In neurophysiology and medicine the term somatosensory system is also commonly used. MacKenzie [14] reviews different models that have been proposed to explain the flow of sensorimotor micro-behaviors during human-computer interaction, such as the Key-Action Model or the Three-State Model for graphical input devices.

The cognitive sub-system functions to appraise incoming information by constructing meaning for it through routine analytic procedures such as providing a coherent context for the information and associating it with other information in memory. Scherer [15] review the past and current literature on "appraisal theory" which attempts to model how emotions are elicited by the individual's cognitive interpretation or assessment of some perceived information about the environment. Appraisal research attempts to identify the cognitive dimensions that predict which emotions are elicited when interpreting information.

The affective sub-system of emotions and motivations determines the consummatory value of the information ("evaluation") and its conative or motivational strength for further action. 0'Shaughnessy [16] identify this consummatory/ conative interaction as a key principle in the successful marketing of information products, which requires "generating emotion" in people:

"If the consumer desires something [=satisficing], he or she contemplates bringing it about[=optimizing]. ... To want product $\mathrm{X}$ is a disposition toward using, consuming, or possessing that product." (p.77).

With the increasing ubiquitous use of wireless technological devices there is a need for understanding the synergistic integration between technology, biology, and social practices. The theory and model presented here may facilitate research on the details of this human-machine symbiosis. While Figure
1 identifies the three components and sub-systems of this integration, Figure 2 provides further details that make it more visible as to the dynamic flow of this synergy in actual motion.A labeling system is indicated which allows reference to parts of the dynamic flow. It will be shown below how this labeling system can be used in further research.

Figure 2 is a general ecological model that describes the social-biological environment that is inherent in all collaborative communication mediated by technology. The social aspects are embodied in the group practices of participants who constrain their individual biological operations to stay within limits of what in the group counts and should be noted, and what is to be ignored in that specific setting or information ground.

A collaborative product or experience is the constructed outcome of coordinated interactions by members, each of whom enacts sensorimotor, cognitive, and affective operations that are adaptive to the group's practices. When members notice a participant's communicative act through a satisficing affordance $\left[\mathrm{E}^{\mathrm{S}} \mathrm{S}^{\mathrm{S}}\right]$ (e.g., a member is heard saying "All right. But what about that one?") [Noticing Practices], they enact cognitive satisficing procedures $\left[\mathrm{C}^{\mathrm{S}}\right]$ that count as appraising this speech act (e.g., relating this new information to what another member previously said about it) [Appraising Practices], and then through affective satisficing procedures $\left[\mathrm{A}^{\mathrm{S}}\right]$ they value-attach it (e.g., "This issue needs to be taken care of right away") [Evaluating Practices].

This three-step satisficing process of noticing, appraising, and evaluating is shown in Figure 2 as the interaction sequence marked by the path $\left[\mathrm{E}^{\mathrm{s}} \mathrm{S}^{\mathrm{s}} \mathrm{C}^{\mathrm{s}} \mathrm{A}^{\mathrm{s}}\right]$. It constitutes the first phase of managing coordination by members mutually. As well, the threestep optimizing process of intending, planning, and executing is shown as the interaction sequence $\left[\mathrm{A}^{0} \mathrm{C}^{0} \mathrm{~S}^{0} \mathrm{E}^{0}\right]$. This second phase consists of optimizing the information by producing modifications in the environment through optimizing affordances. These two alternating phases of joint construction describe what is going on moment by moment in the collaborative or social activity.

Intersubjectivity and group identity emerge and evolve as long as coordination is maintained by participants through progressive interactionism. This sustained and persistent coordination is accomplished by participants when they satisfice each other's activity $\left[\mathrm{E}^{\mathrm{S}} \mathrm{S}^{\mathrm{s}} \mathrm{C}^{\mathrm{S}} \mathrm{A}^{\mathrm{S}}\right]$, and then optimize it through goal-intentions that they enact and execute with affordances in order to make it available to the noticing of other participants $\left[\mathrm{A}^{0} \mathrm{C}^{0} \mathrm{~S}^{0} \mathrm{E}^{0} \mathrm{E}^{\mathrm{S}} \mathrm{S}^{S}\right]$. This alternating sequential process of interpersonal satisficing and optimizing, endlessly iterative, constitutes computer mediated collaboration.

Figure 2 is a theory of intersubjectivity specifying how collaborative interaction produces shared understanding that enables individuals to be productive members of a team or group. This reflexivity is a characteristic of all constitutive systems [16]. Collaborative construction is accomplished when each individual maintains sensorimotor, cognitive, and affective operations within the limits of satisficing and optimizing that are embodied in the group's practices. Social communication practices in a group are embodied in the coordinated interactions 


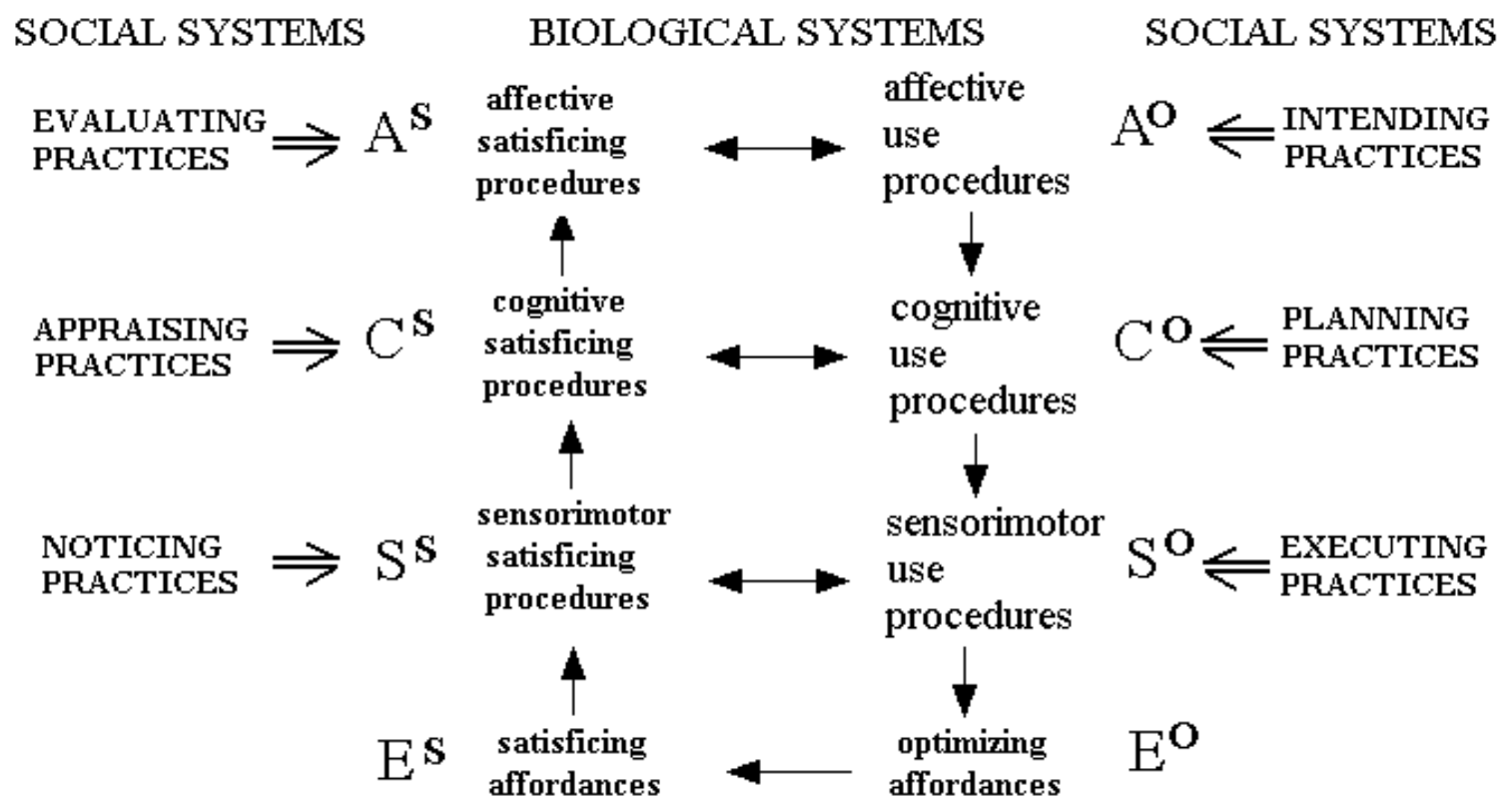

\section{TECHNOLOGICAL SYSTEMS}

Figure 2: Ecological Constructionism Model.

of members along the threefold biological system. Hence it is important theoretically and practically to identify the sequence of this jointly managed activity. Figure 2 offers a methodology for possibly charting the flow of progressive interactionism in online communication and socializing.

The social process that transforms an individual into a member can be represented as the process of participating in the joint construction of the intersubjective 'space' or information ecology. When people first join a collaborative group activity they are recognized by others as novices or new arrivals. This means that members tolerate activity by the novice that does not contribute to the joint construction of the interaction environment. Increasingly and progressively, the novice is perceived as contributing to the coordination of collaborative activity. Newcomers achieve this successful appearanceby managing their satisficing and optimizing procedures through the use of the same affordances that members use. At some point the novice status of the individual vanishes from the ecology, as it is no longer supported and embodied by the current matured activity.

The theory of ecological constructionism Nahl [10,11] specifies the interaction framework that integrates information systems with the individual's biological or mental operations. In the process of interacting with others through the intermediary of technological affordances, individuals adjust these biological or mental operations to operate within the limits that satisfice the group practices, and thus fully meeting the conditions for being considered a normal response.

In other words, other members in the group or community notice and appraise each other's operations as normal for that situation and context. Novice users or aspiring members are noticed immediately by others because these new arrivals have not yet achieved normalcy in their biological operations, as for example, not noticing something about a message that others notice, or evaluating it differently than others do. Idiosyncratic or stylistic distinctions are allowable but they must stay within the bounds that are satisficed by participants as normal for that situation.

Information reception within a group or team involves the logic of satisficing that was formulated by Simon [8,9], often expressed in the literature as "setting an aspiration level which, if achieved, they will be happy enough with." An individual maintains membership in a group as long as others satisfice the individual's actions as normal enough for that situation. The action of one participant is satisficed by the others when they count it as good enough to fit normalcy for the situation.

Once information about someone's action has been received and satisficed by another individual $\left[\mathrm{E}^{\mathrm{s}} \mathrm{S}^{\mathrm{s}} \mathrm{C}^{\mathrm{s}} \mathrm{A}^{\mathrm{s}}\right]$, the reverse sequence of operations can be performed to optimize the information $\left[\mathrm{A}^{0} \mathrm{C}^{0} \mathrm{~S}^{0} \mathrm{E}^{0}\right]$. First, affective optimizing procedures $\left[\mathrm{A}^{0}\right]$ can be performed that count as practices of intending to engageor as motivated goal-settingpractices. Second, cognitive optimizing procedures $\left[\mathrm{C}^{0}\right]$ are performed that count as planningpractices. Third, sensorimotor optimizing procedures $\left[\mathrm{S}^{0} \mathrm{E}^{0}\right]$ are performed that count as executing with available optimizing affordances.

This action or intervention is then displayed as information $\left[\mathrm{E}^{\mathrm{S}} \mathrm{S}^{\mathrm{S}}\right]$ that is satisficed by others $\left[\mathrm{C}^{\mathrm{S}} \mathrm{A}^{\mathrm{S}}\right]$. Collaborative or social 
activity consists of the continuous cycling of mutually satisficing and optimizing each other's interventions. This process of social-biological interactionism creates and maintains the intersubjective environment of shared understandings and group identity.

\section{Research Directions and Implications for Interface Design}

To illustrate, we can apply the theory of ecological constructionism to Norman's model (2004:51) that defines a "gulf of execution" as "the difference between the [user's] intentions and the allowable actions." This relationship is depicted on Figure 2 as the relation between intending a goal $\left[\mathrm{A}^{0}\right]$ and its execution through the use of available optimizing affordances $\left[\mathrm{S}^{0} \mathrm{E}^{0}\right]$. The figure makes it clear that the "gulf" of execution consists of the cognitive optimizing procedures $\left[\mathrm{C}^{0}\right]$ of planning, without which the goal cannot be executed $\left[\mathrm{S}^{0} \mathrm{E}^{0}\right]$.

In collaborative efforts or social exchanges mediated by technology two or more users are wired into the interactional circuit as follows:

(1) $\left[E^{S} S^{S}\right]$ noticing the information on the display through sensorimotor satisficing procedures (e.g., "something is there")

(2) $\left[\mathrm{S}^{\mathrm{s}} \mathrm{C}^{\mathrm{S}}\right]$ appraising the noticed information according to group practices through cognitive satisficing procedures (e.g., "what is it")

(3) $\left[\mathrm{S}^{\mathrm{S}} \mathrm{A}^{\mathrm{S}}\right]$ evaluating the appraised information through affective satisficing procedures (e.g., "what is its value to others")

(4) $\left[\mathrm{A}^{\mathrm{O}}\right]$ affective optimizing procedures of having an intention (intentionality) or being motivated to engage or interact (e.g., "what I am going to do about it")

(5) $\left[\mathrm{A}^{0} \mathrm{C}^{0}\right]$ working out the planning details with cognitive optimizing procedures (e.g., "I have to do this before that")

(6) $\left[\mathrm{C}^{0} \mathrm{C}^{\mathrm{S}}\right]$ appraising the planning before executing (e.g. "how will this be interpreted")

(7) $\left[\mathrm{S}^{0} \mathrm{E}^{0}\right]$ executing the plan through sensorimotor optimizing procedures with optimizing affordances (e.g., clicking sending, searching)

(8) $\left[E^{S} S^{S}\right]$ noticing the changes on the screen or other satisficing affordance (e.g., "who could have seen it")

(9) $\left[\mathrm{S}^{\mathrm{S}} \mathrm{C}^{\mathrm{S}}\right]$ appraising the results (e.g., "what does this mean")

(10) $\left[\mathrm{A}^{\mathrm{S}} \mathrm{A}^{0}\right]$ evaluating the new information and intending new planning $\left[\mathrm{C}^{\circ}\right]$ and execution $\left[\mathrm{S}^{\circ} \mathrm{E}^{0}\right]$.

Communication problems potentially arise at each node in Figure 2. For instance, collaborators may be exposed simultaneously to the same satisficing affordances $\left[\mathrm{E}^{\mathrm{S}}\right]$ but not notice the same information $\left[\mathrm{E}^{\mathrm{S}} \mathrm{S}^{\mathrm{S}}\right]$, or, they may appraise the same information differently $\left[\mathrm{S}^{\mathrm{s}} \mathrm{C}^{\mathrm{S}}\right]$, or, they may evaluate it from different standards $\left[\mathrm{C}^{\mathrm{s}} \mathrm{A}^{\mathrm{S}}\right]$. These differences may alter the optimizing intentions $\left[\mathrm{A}^{0}\right]$, or the planning moves $\left[\mathrm{C}^{0}\right]$, and consequently modify the execution procedures with the available technology $\left[\mathrm{S}^{0} \mathrm{E}^{0}\right]$. To the extent that this occurs, to that extent the collaboration or social cohesion loses efficiency or effectiveness. Technology design features that assist collaborators in identifying the location of such problems can help restore efficiency.

Interacting individuals each manage their own noticings $\left[\mathrm{E}^{S} \mathrm{~S}^{S}\right]$, appraisings $\left[\mathrm{C}^{S}\right]$, and evaluating procedures $\left[\mathrm{A}^{S}\right]$ in such a way as to achieve a mutual interdependence so that they may continue interacting. The success or effectiveness of each participant in the collaborative activity depends on the group practices involving satisficing. This refers to the evaluation that one participant makes of another participant's particular action $\left[\mathrm{S}^{0} \mathrm{E}^{0} \mathrm{E}^{\mathrm{S}} \mathrm{S}^{\mathrm{S}} \mathrm{C}^{\mathrm{S}} \mathrm{A}^{\mathrm{S}}\right]$, that is, whether this action is normal for the conditions or situation. Whenever some action appears not normal, participants cannot satisfice it as normal, thus reject it as not a part of the group's ordinary activity. The interaction cycle is thus broken and the group begins to disintegrate.

The breakdown of collaboration is not due to differences of opinion or disagreements about evaluation and priorities. Both agreements and disagreements are part of the normal satisficing activity in any group. Breakdown occurs when acts can no longer be satisficed, as a result of which interactionism ceases. Examples include:

- $\quad$ talking gibberish

- $\quad$ using words in an unknown way

- $\quad$ talking about something as if it had been discussed before when it hasn't

- holding on to presuppositions and background assumptions that others do not know about

- $\quad$ responding negatively to every idea

- $\quad$ acting like a stranger with friends

- $\quad$ answering without listening

- $\quad$ using speech acts idiosyncratically

- $\quad$ and so on.

Collaborative productivity and effectiveness begin to deteriorate when these anti-interactionism procedures reach some critical mass relative to the normalizing interactions. Hence, the satisficing actions of participants in social settings are an important aspect of managing the continuation and success of collaborative activity. Satisficing is therefore an essential component of social interaction and team productivity.

Figure 2 points to six areas of potential research in understanding online user behavior:

(1) $\left[E^{S} S^{S} A^{S}\right]$ [sensorimotor and affective satisficing] What user procedures lead to biased noticings of display features, so that some critical features are ignored or unnoticed

(2) $\left[\mathrm{S}^{\mathrm{s}} \mathrm{C}^{\mathrm{S}}\right]$ [sensorimotor and cognitive satisficing] What user procedures lead to inadequate or incomplete appraisal of incoming information, where wrong conclusions are made 
(3) $\left[\mathrm{C}^{\mathrm{S}} \mathrm{A}^{\mathrm{S}}\right] \quad$ [cognitive and affective satisficing $]$ What user procedures lead to resistive satisficing states, where rejection is premature vs. enthusiasm and loyalty

(4) $\left[\mathrm{A}^{\mathrm{S}} \mathrm{A}^{\mathrm{o}} \mathrm{A}^{\mathrm{S}}\right]$ [affective satisficing and affective optimizing] What user procedures enhanceoptimizing with appropriategoalsetting and regulating vs. wrong headed and ineffective

(5) $\left[\mathrm{A}^{\circ} \mathrm{C}^{0}\right]$ [affective and cognitive optimizing] What user procedures lead to goal-directed planning and problem solving vs. inconsistent reasoning

(6) $\left[\mathrm{A}^{\mathrm{O}} \mathrm{C}^{\mathrm{O}} \mathrm{S}^{\mathrm{o}} \mathrm{E}^{\mathrm{o}}\right]$ [affective, cognitive, and sensorimotor optimizing] What user procedures optimize performance and develop automaticity with less errors

The first three areas focus on satisficing issues while the other three focus on optimizing issues. User procedures refer to the behavior circuits that an individual performs when satisficing input from the computer and optimizing goal-intentions through planned action or response. Making errors is not a random activity. Users must follow particular behavior circuits to achieve those errors. Each error is an accomplishment, i.e., a particular step-by-step procedure had to be followed to commit that error. Similarly with other user attributes such as:

(i) being distracted by insufficient goal regulation in problem solving sequences $\left[\mathrm{A}^{0} \mathrm{C}^{0}\right]$

(ii) forgetting things, by not optimizing goal-setting and not satisficing higher

(iii) maintaining standards of accuracy and precision $\left[\mathrm{A}^{0} \mathrm{C}^{0}\right.$ $\left.\mathrm{C}^{\mathrm{s}} \mathrm{A}^{\mathrm{s}} \mathrm{A}^{0}\right]$

(iv) being impatient and missing available solutions $\left[\mathrm{A}^{\mathrm{S}} \mathrm{A}^{0} \mathrm{~S}^{0}\right]$

(v) feeling suspicious of the system, resisting following instructions $\left[\mathrm{E}^{\mathrm{S}} \mathrm{S}^{\mathrm{S}} \mathrm{A}^{\mathrm{s}} \mathrm{A}^{\mathrm{o}} \mathrm{C}^{\mathrm{O}} \mathrm{S}^{\mathrm{o}} \mathrm{S}^{\mathrm{S}}\right]$ $\mathrm{S}^{\mathrm{o}} \mathrm{S}^{\mathrm{S}}$

(vi) feeling enthusiasm and single minded in focus $\left[\mathrm{A}^{0} \mathrm{~A}^{\mathrm{S}} \mathrm{A}^{0}\right.$

The integrated behavior-environment model in Fig. 1 is general enough to make explicit the sub-components of human agency in a variety of information settings, e.g., performing computer tasks, online searching, online shopping or designing integrated human-machine satisficing-optimizing systems. Future research will explore to what extent the coding procedure based on Fig. 1 can be computationally implemented, allowing the modeling of user attributes at the micro-level of representation and monitoring.

Research is needed to map the network of behavioral circuits, and how they are established by an individual to produce characteristic satisficing and optimizing procedures in information settings. With a focus on optimizing, it is useful to classify the optimizing stream of behavior into three levels corresponding to the three memories: long term, short term and sudden. Long-term behavior circuits involve goal-setting plans that are optimized longitudinally, such as career goals or lifestyle strivings. Short-term goals use behavior circuits that run task performance, while sudden goals are micro-circuits that tend to be automated. The three levels of goals and the three channels of operation define an ennead matrix of nine zones that can be used to map out, monitor and influence how users behave in information settings. Nahl [17] has described several applications of the ennead matrix to information seeking behavior.

\section{References}

1. Mead GH (1934) Mind Self and Society. In: C.W. Morris (Ed.), University of Chicago, Chicago, USA.

2. Habermas J (1984) The theory of communicative action. Beacon Press ,Boston, USA.

3. Floridi L (2007) A look into the future impact of ICT on our lives. The Information Society: An International Journal 23(1): 59-64.

4. McGonigal J (2011) Reality is Broken: Why Games Make us Better and How They Can Change the World. The Penguin Press, New York, USA.

5. Gibson EJ, Pick AD (2000) An ecological approach to perceptual learning and development. Oxford University Press, Oxford, UK.

6. Norman DA (2003) Emotional design: why we love (or hate) everyday things. Basic Books, New York, USA.

7. Norman DA (1981) Twelve issues for cognitive science. In: DA Norman (Ed.), Perspectives on cognitive science. Erlbaum, Basic Books, Hillsdale, New Jersey, USA, pp. 265-295.

8. Simon HA (1982) Theories of bounded rationality. In Models of bounded rationality. Behavioral Economics and Business Organization. MIT Press, Cambridge, London, UK, pp. 408-423.

9. Simon HA (1956) Rational choice and the structure of the environment. Psychological Review 63(2): 129-138.

10. Nahl D (2007a) Domain Interaction Discourse Analysis: A Technique for Charting the Flow of Micro-Information Behavior. Journal of Documentation 63(3): 323-339.

11. Nahl D (2007b) Social-biological information technology: an integrated conceptual framework. Journal of the American Society for Information Science and Technology 58(13): 2021-2046.

12. Nahl D, Bilal D (2007) Information and emotion. In: Nahl D, Bilal D (eds.), ITL, Medford, New Jersey, USA.

13. MacKenzie S (2003) Motor behavior models for human-computer interaction. In: JM Carroll (Ed.), HCI models theories and frameworks: toward a multidisciplinary science. Morgan Kaufmann, New York, USA, pp.27-54.

14. Scherer K, Schorr A, Johnstone T (2001) Appraisal processes in emotion: theory, methods, research. In: Scherer K, Schorr A, Johnstone T (Eds.) Oxford University Press, New York, USA.

15. Shaughnessy J, O Shaughnessy NJ (2003) The marketing power of emotion. Oxford University Press, New York, USA.

16. Searle J (1995) The construction of social reality. Penguin, London, UK.

17. Nahl Diane (2001) A conceptual framework for defining information behavior. Studies in Multimedia Information Literacy Education. University of Toronto Press, Canada. 